\title{
External Sector Rebalancing and Endogenous Trade Imbalance Models
}

\author{
John Whalley ${ }^{1,2}$
}

ABSTRACT

\begin{abstract}
I discuss the need for trade models to incorporate endogenous trade imbalances both to more adequately capture the reality of a global economy with large imbalances and pressures from the financial crisis for countries to reduce imbalances. Conventional general equilibrium trade models implicitly incorporate monetary neutrality and either have zero trade balance as a property of equilibrium, or have a fixed and exogenous trade imbalance. Models which are discussed here have a variety of forms. In one, central banks fix exchange rates and operate a non accommodative monetary policy and accumulate reserves. Changes in both trade and monetary policies change reserve accumulative and with the external sector imbalances. This is a reflection of China's current policy regime. In another intertemporal preferences allow for simultaneous inter commodity and intertemporal trade across countries, and with changed intertemporal trade changed external sector imbalances within the period. These formulations are each applied to potential tax initiatives to aid in rebalancing.
\end{abstract}

KEY WORDS: $\quad$ endogenous trade model, general equilibrium, external sector imbalances

JEL Classification: F11, C68, F42, F32

${ }^{1}$ University of Western Ontario, Canada, ${ }^{2}$ National Bureau of Economic Research (NBER)

\section{Introduction}

Rebalancing refers to the reduction of large aggregate imbalances, covering trade (and current account) imbalances, public sector deficits, and high savings rates in some countries and low savings rates in others. Here I discuss the use of trade models with endogenously determined external sector imbalances to analyze rebalancing options. Conventional general equilibrium trade models typically incorporate monetary neutrality and have zero trade balance as a property of equilibrium, or specify a fixed and exogenous trade imbalance. Here I discuss two different formulations

Corespondence concerning this article should be addressed to: John Whalley, Department of Economics, Faculty of Social Science The University of Western Ontario, London, Ontario N6A 5C2, CANADA, Phone: (519) 661-3509, Fax: (519) 661-3064, e-mail: jwhalley@uwo.ca of equilibrium models which allow for imbalances to both occur and change.

\section{Endogenous Trade Imbalance Models}

Conventional real side trade models (see Dixit \& Norman (1980)) sit as a subclass of general equilibrium models of pure barter form, which if taken to a simple monetized extension via a simple quantity theory of money approach exhibit neutrality of money. In these, in 2 country form, once domestic money supplies are determined exchange rates are endogenously determined in such a way that changes in monetary policy only affect exchange rates with no real effects. In such models, in addition, trade balance by country is either zero as a property of equilibrium; or meets an exogenously given inter country transfer, which is fixed and given and implies an exogenous trade imbalance. 
To capture endogenous trade imbalances and to yield models that can be useful in providing inputs into debate on rebalancing some modification or extension is needed. Here I focus on two such extensions. One involves a monetary non-neutrality specified via the exchange rate regime and policies of central banks. The other has a simple intertemporal extension to a conventional single period real side model via inside money.

\subsection{An Endogenous Trade Imbalance Model with Monetary Non Neutralities}

I first consider a typical $2 \times 2 \times 2$ model with two countries, two goods and two factors of production per country. I use the Armington assumption under which domestic goods and imported goods are heterogeneous to accommodate cross hauling in trade data, and also to remove specialization problems with the model which is important if the model is to be used in numerical simulation. The two input factors are labor and capital which are immobile across countries, but mobile across sectors.

On the production side, I will assume CES functions for each product in each country:

$$
\begin{aligned}
& Q_{i}^{j}=\phi_{i}^{j}\left[\delta_{i}^{j}\left(L_{i}^{j}\right)^{\frac{\sigma_{i}^{j}-1}{\sigma_{i j}^{j}}}+\left(1-\delta_{i}^{j}\right)\left(K_{i}^{j}\right)^{\frac{\sigma_{i}^{j}-1}{\sigma_{i}^{j}}}\right]^{\frac{\sigma_{i}^{j}}{\sigma_{i}^{j}-1}}, \\
& i=\text { sector }, j=\text { country }
\end{aligned}
$$

where $Q_{i}^{j}$ is the output of the $i^{t h}$ industry in country $j, L_{i}^{j}$ and $K_{i}^{j}$ are the labor and capital inputs, $\phi_{i}^{j}$ is the scale parameter, $\delta_{i}^{j}$ is the distribution parameter and $\sigma_{i}^{j}$ is the elasticity of factor substitution.

First order conditions for cost minimization imply the factor input demand equations ${ }^{1}$,

$K_{i}^{j}=\frac{Q_{i}^{j}}{\phi_{i}^{j}}\left[\delta_{i}^{j}\left[\frac{\left(1-\delta_{i}^{j}\right) P_{L}^{j}}{\delta_{i}^{j} P_{K}^{j}}\right]^{\left(1-\sigma_{i}^{j}\right)}+\left(1-\delta_{i}^{j}\right)\right]^{\frac{\sigma_{i}^{\prime}}{1-\sigma_{i}^{j}}}$

$L_{i}^{j}=\frac{Q_{i}^{j}}{\phi_{i}^{j}}\left[\delta_{i}^{j}+\left(1-\delta_{i}^{j}\right)\left[\frac{\delta_{i}^{j} P_{K}^{j}}{\left(1-\delta_{i}^{j}\right) P_{L}^{j}}\right]^{\left(1-\sigma_{i}^{j}\right)}\right]^{\frac{\sigma_{l}^{j}}{1-\sigma_{i}^{j}}}$

where $P_{K}^{j}$ and $P_{L}^{j}$ are the prices of capital and labor in country $j$.

On the consumption side, I assume nested CES utility functions with an added labor-leisure choice in each country to capture efficiency effects of any rebalancing analysis on the supply side. These nested functions, with three levels, are set out in Figure 1. The first level captures the consumption leisure choice, the second the domestic imported good choice, and the third the more detailed product choice among the 2 goods.

Equilibrium in this model is then given by market clearing prices for goods and factors in each country such that

$Q_{i}^{j}=D_{i}^{j}+X_{i}^{j} \quad i, j=1,2$

$\sum_{i} L_{i}^{j}=\bar{L}^{j}-$ Lei $_{i} \quad j=1,2$

$\sum_{i} K_{i}^{j}=\bar{K}^{j} \quad j=1,2$

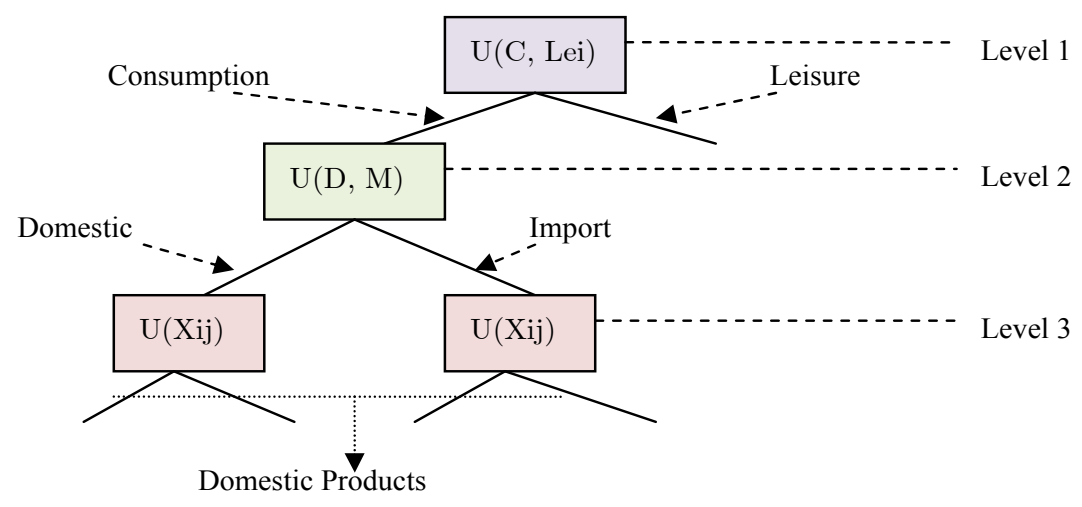

Figure 1. Nesting Structure of CES Utility Functions in the Monetary Non Neutrality Model 
where $D_{i}^{j}$ is consumption of domestic good $i$ in country $j$, and $X_{i}^{j}$ is the export of goods $i$ by country $j ; \bar{L}^{j}$ and $\bar{K}^{j}$ are endowments of labor and capital, and $L e i_{i}$ is leisure consumption by country $i$.

Exports of good $i$ by country $j$ are denoted as $X_{i}^{j}$, and are the difference between output and domestic demand. Import of good $i$ by country $j$ are denoted as $M_{i}^{j}$, and equal the other country's export of good $i$ in a two country case.

$X_{i}^{j}=Q_{i}^{j}-D_{i}^{j}$

$M_{i}^{j}=X_{i}^{h}=Q_{i}^{h}-D_{i}^{h} \quad h, j=$ country $, h, j=1,2 ; h \neq j$

To accommodate a trade surplus or deficit as an endogenous variable in this structure, I use a monetized extension incorporating a fixed exchange rate and nonaccommodative monetary policy, similar to that in Whalley and Wang (2011). In this formulation prices are denominated in domestic currency with an exchange rate e between the two domestic moneys. Cross country arbitrage between the country specific prices yields:

$p_{i}^{j}=e p_{i}^{i} \quad i, j=1,2 ; \quad i \neq j$

The net trade surplus $S^{j}$ in country $j$ is:

$S^{j}=\sum_{i} p_{i}^{j} X_{i}^{j}-\sum_{i} p_{i}^{j} M_{i}^{j}$

where $P_{i}^{j}$ is the producer price of the $i^{\text {th }}$ product in country $j$. If there is trade balance

$\sum_{i} P_{i}^{j} X_{i}^{j}=\sum_{i} P_{i}^{j} M_{i}^{j}$

as in a conventional model. Also if money only enters the model via the transactions demand for money in each country and for simplicity unitary velocity is assumed, the money demand in country $\mathrm{j}$ is:

$\sum_{i}\left(\hat{p_{i}^{j}} D_{i}^{j}+\hat{p}_{i}^{j} M_{i}^{j}\right)=\bar{M}^{j}$

It is also assumed that exporters are paid in their own country currency, where $\hat{p}_{i}^{j}$ is the consumer price of product $i$ in country $j$, and $\bar{M}^{j}$ is country $j^{\prime} s$ money supply. In traditional models, money is neutral in the sense that once domestic money supplies are specified, an equilibrium exchange rate is determined indepen- dently of the real side, and a fixed exchange rate regime and trade surplus does not occur. If the exchange rate $e$ is fixed at $\bar{e}$, then the relative domestic money stocks $\bar{M}^{i} / \bar{M}^{j}$ need to accommodate to $\bar{e}$ so as to support it as an equilibrium exchange rate. In this structure the monetary regime can be non-accommodative to the fixed exchange rate through the accumulation of reserves at the fixed exchange rate. In this case the trade surplus will be endogenously determined.

If country 1 has a trade surplus $S^{1}$ and country 2 has a trade deficit $\mathrm{D}^{2}$,

$$
\begin{aligned}
& S^{1}=\sum_{i} p_{i}^{1} X_{i}^{1}-\sum_{i} p_{i}^{1} M_{i}^{1} \\
& D^{2}=\sum_{i} p_{i}^{2} M_{i}^{2}-\sum_{i} p_{i}^{2} X_{i}^{2}
\end{aligned}
$$

country 1's trade surplus will equal country 2's trade deficit in equilibrium, and country money demands are:

$$
\begin{aligned}
& \bar{M}^{1}=\sum_{i} p_{i}^{1} Q_{i}^{1} \\
& \bar{M}^{2}=\sum_{i} p_{i}^{2} Q_{i}^{2}+S^{1}
\end{aligned}
$$

The equilibrium conditions for the model remain (4), (5) and (6), but at the fixed exchange rate trade imbalances $\mathrm{S}^{1}$ and $\mathrm{D}^{2}$ are endogenously determined.

\subsection{An Endogenous Trade Imbalance Model with Intertemporal Structure}

I next discuss a general equilibrium model with international trade in goods to which monetary structure using inside money is added. This allows for the endogenous determination of trade imbalances for trade in goods, which is offset through intertemporal trade across countries in money. The monetary structure builds on Azariadis (1993) where there is extensive discussion of simple overlapping generation models with inside money. In analyzing trade, interactions between monetary structure and commodity trade are needed, and hence models with simultaneous intertemporal and inter-commodity structure.

In this general equilibrium model with monetary structure, I assume there are two goods in each period and allow inter-commodity trade to co-exist within the period along with trade in debt in the form of inside money. I use a single period model where either 
claims on future consumption (money holding) or future consumption liabilities (money insurance) enter the utility function as incremental future consumption from current period savings. This is the formulation of inside money used by Patinkin $(1947 ; 1971)$ and Archibald and Lipsey (1960). This can also be used in a multi-country model structure with trade in both goods and inside money.

The general equilibrium model has multiple countries, and each country produces two goods with two factors. The two goods are tradable goods and nontradable goods. The two factors are labor and capital.

On the consumption side, I again use the Armington assumption of product heterogeneity across countries, and assume claims on future consumption enter preferences and are traded between countries. Each country can thus either issue or buy claims on future consumption using current period income. I use a nested CES utility function to capture consumption behaviour,

$$
\begin{aligned}
& U_{i}\left(X_{i}^{T}, X_{i}^{N T}, Y_{i}\right)=\left[\alpha_{i 1}^{\frac{1}{\sigma_{i}}}\left(X_{i}^{T}\right)^{\frac{\sigma_{i}-1}{\sigma_{i}}}+\alpha_{i 2}^{\frac{1}{\sigma_{i}}}\left(X_{i}^{N T}\right)^{\frac{\sigma_{i}-1}{\sigma_{i}}}+\right. \\
& \left.+\alpha_{i 3}^{\frac{1}{\sigma_{i}}}\left(Y_{i}\right)^{\frac{\sigma_{i}-1}{\sigma_{i}}}\right]^{\frac{\sigma_{i}}{\sigma_{i}-1}}, \quad i=\text { country }
\end{aligned}
$$

where $X_{i}^{N T}$ denotes the consumption of non-tradable goods in country $i, X_{i}^{T}$ denotes the consumption of Armington composite tradable goods in country $i, Y_{i}$ denotes the inside money for country $i . \alpha_{i 1}, \alpha_{i 2}$ and $\alpha_{i 3}$ are share parameters and $\sigma_{i}$ is the elasticity of consumption substitution.

Here, inside money $Y_{i}$ also represents country i's trade imbalance. $Y_{i}>0$ implies a trade surplus (or claims on future consumption); $Y_{i}<0$ implies a trade deficit or future consumption liabilities (money issuance), and $Y_{i}=0$ implies trade balance. For trade deficit countries, utility will decrease in inside money since they are issuers. In order to capture this, I use an upper bound $Y^{0}$ in the utility function in a term $\left[Y^{0}+Y_{i}\right]$ following Whalley, Yu and Zhang (2011), and assume that $Y^{0}$ is large enough to ensure that $Y^{0}+Y_{i}>0$.

I summarize the nesting structure used in consumption and production in Figure 2. The composite of tradable goods defines another nesting level reflecting the country from which goods come. I assume this level 2 composite consumption is of CES form and defined as,

$X_{i}^{T}=\left[\sum_{j} \beta_{i j}^{\frac{1}{\sigma_{i}^{\prime}}} x_{i j}^{T} \frac{\sigma_{i}^{\prime}-1}{\sigma_{i}^{\prime}} \frac{\sigma_{i}^{\prime}}{\sigma^{\sigma_{i}-1}} \quad j=\right.$ country where $X_{i j}^{T}$ is the consumption of tradable goods from country $j$ in country $i$. If $i=j$ this country consumes its domestic produced tradable goods. $\beta_{i j}$ is the share parameter for country $j$ 's tradable goods consumed in country $i . \sigma_{i}^{\prime}$ is the elasticity of substitution in level 2 in country $i$.

For a representative consumer in country $i$ their income is $I_{i}$, and maximizing utility subject to budget constraint yields

$X_{i}^{T}=\frac{\alpha_{i 1} I_{i}}{\left(P_{i}^{T}\right)^{\sigma}\left[\alpha_{i 1}\left(P_{i}^{T}\right)^{1-\sigma}+\alpha_{i 2}\left(p c_{i}^{N T}\right)^{1-\sigma}+\alpha_{i 3}\left(p c_{i}^{Y}\right)^{1-\sigma}\right]}$

$X_{i}^{N T}=\frac{\alpha_{i 2} I_{i}}{\left(p c_{i}^{N T}\right)^{\sigma}\left[\alpha_{i 1}\left(P_{i}^{T}\right)^{1-\sigma}+\alpha_{i 2}\left(p c_{i}^{N T}\right)^{1-\sigma}+\alpha_{i 3}\left(p c_{i}^{Y}\right)^{1-\sigma}\right]}$

$Y_{i}=\frac{\alpha_{i 3} I_{i}}{\left(p c_{i}^{Y}\right)^{\sigma}\left[\alpha_{i 1}\left(P_{i}^{T}\right)^{1-\sigma}+\alpha_{i 2}\left(p c_{i}^{N T}\right)^{1-\sigma}+\alpha_{i 3}\left(p c_{i}^{Y}\right)^{1-\sigma}\right]}$

Budget constraints apply for each country $i$ in the form

$P_{i}^{T} X_{i}^{T}+p c_{i}^{N T} X_{i}^{N T}+p c_{i}^{Y} Y_{i}=I_{i}=w_{i}^{K} \overline{K_{i}}+w_{i}^{L} \overline{L_{i}}$

and $p_{i}^{T}, p c_{i}^{N T}$ and $p c_{i}^{Y}$ are separately consumption prices of composite tradable goods, non-tradable goods and inside money in country $i$.

If I use the transformation $y_{i}=Y^{0}+Y_{i}$ to solve the optimization problem, the utility function and budget constraint become

$\operatorname{Max}_{i}\left(X_{i}^{T}, X_{i}^{N T}, Y_{i}\right)=\left[\alpha_{i 1}^{\frac{1}{\sigma_{i}}}\left(X_{i}^{T}\right)^{\frac{\sigma_{i}-1}{\sigma_{i}}}+\right.$

$\left.+\alpha_{i 2}^{\frac{1}{\sigma_{i}}}\left(X_{i}^{N T}\right)^{\frac{\sigma_{i}-1}{\sigma_{i}}}+\alpha_{i 3}^{\frac{1}{\sigma_{i}}}\left(y_{i}\right)^{\frac{\sigma_{i}-1}{\sigma_{i}}}\right]^{\frac{\sigma_{i}}{\sigma_{i}-1}}$

s.t. $P_{i}^{T} X_{i}^{T}+p c_{i}^{N T} X_{i}^{N T}+p c_{i}^{Y} y_{i}=I_{i}+p c_{i}^{Y} Y^{0} \equiv I_{i}^{*}$

The solutions to (18) are as in (16), but $Y_{i}$ changes to $y_{i}$.

The composite tradable goods enter the second level and come from different countries, and the country specific demands are

$x_{i j}^{T}=\frac{\beta_{i j}\left(X_{i}^{T} P_{i}^{T}\right)}{\left(p c_{i j}^{T}\right)^{\sigma_{i}}\left[\sum_{j} \beta_{i j}\left(p c_{i j}^{T}\right)^{\left(1-\sigma_{i}^{\prime}\right)}\right]}$

where $p c_{i j}^{T}$ is the consumption price of tradable goods in country $i$ from country $j$ (produced in country $j$ ), $X_{i}^{T} P_{i}^{T}$ is the total expenditure on tradable goods in country $i$. The consumption price for the composite of tradable goods is 
Production Function (CES)

Consumption Function (CES)
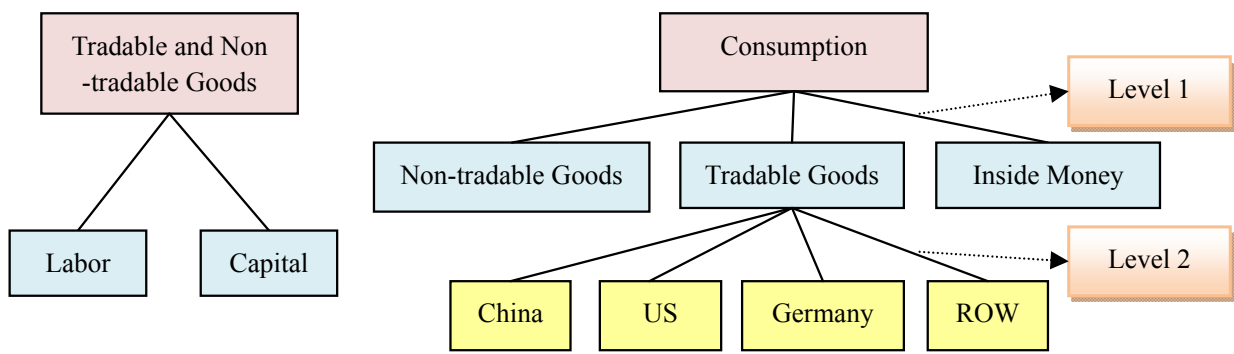

Figure 2. Nesting Structure of Production and Consumption Functions Used in the Inter Temporal Model Functions

$$
P_{i}^{T}=\left[\sum_{j=1}^{4} \beta_{i j}\left(p c_{i j}^{T}\right)^{\left(1-\sigma_{i}^{\prime}\right)}\right]^{\frac{1}{1-\sigma_{i}^{\prime}}}
$$

On the production side, I again assume CES technology for production of each good in each country

$Q_{i}^{l}=\phi_{i}^{l}\left[\delta_{i}^{l}\left(L_{i}^{l}\right)^{\frac{\sigma_{i}^{l}-1}{\sigma_{i}^{l}}}+\left(1-\delta_{i}^{l}\right)\left(K_{i}^{l}\right)^{\frac{\sigma_{i}^{l}-1}{\sigma_{i}^{l}}}\right]^{\frac{\sigma_{i}^{l}}{\sigma_{i}^{l}-1}}$,

$i=$ country, $l=$ industry

where $Q_{i}^{l}$ is the output of the $l^{\text {th }}$ industry (including tradable goods and non-tradable goods) in country $i$, $L_{i}^{l}$ and $K_{i}^{l}$ are the labor and capital inputs, $\phi_{i}^{l}$ is the scale parameter, $\delta_{i}^{l}$ is the distribution parameter and $\sigma_{i}^{l}$ is the elasticity of factor substitution. First order conditions for cost minimization imply the factor input demand equations,

$K_{i}^{l}=\frac{Q_{i}^{l}}{\phi_{i}^{l}}\left[\delta_{i}^{l}\left[\frac{\left(1-\delta_{i}^{l}\right) w_{i}^{L}}{\delta_{i}^{l} w_{i}^{K}}\right]^{\left(1-\sigma_{i}^{l}\right)}+\left(1-\delta_{i}^{l}\right)\right]^{\frac{\sigma_{i}^{l}}{1-\sigma_{i}^{l}}}$

$L_{i}^{l}=\frac{Q_{i}^{l}}{\phi_{i}^{l}}\left[\delta_{i}^{l}+\left(1-\delta_{i}^{l}\right)\left[\frac{\delta_{i}^{l} w_{i}^{K}}{\left(1-\delta_{i}^{l}\right) w_{i}^{L}}\right]^{\left(1-\sigma_{i}^{l}\right)}\right]^{\frac{\sigma_{l}^{l}}{1-\sigma_{i}^{l}}}$

For global trade (or money) clearance,

$\sum_{i} Y_{i}=0$

Equilibrium in the model in then given by market clearing prices for goods and factors in each country such that
$\left\{\begin{array}{l}Q_{i}^{T}=\sum_{j} x_{j i}^{T} \\ Q_{i}^{N T}=X_{i}^{N T}\end{array}\right.$

$$
\left\{\begin{array}{l}
\sum_{l} K_{i}^{l}=\overline{K_{i}} \\
\sum_{l} L_{i}^{l}=\overline{L_{i}}
\end{array}\right.
$$

where $Q_{i}^{T}$ and $Q_{i}^{N T}$ are separately output of tradable goods and non-tradable goods in country $i$. A zero profit condition must be satisfied in each industry in each country, such that

$p_{i}^{l} Q_{i}^{l}=w_{i}^{K} K_{i}^{l}+w_{i}^{L} L_{i}^{l} \quad l=T, N T$

where $p_{i}^{l}$ is the producer price of goods $l$ in country $i$. In this general equilibrium model with inside money, deficits and surpluses in goods trade are endogenously determined and policy options towards rebalancing can be also considered.

\section{Using the Models to Assess Policy Options Towards Rebalancing}

The models set out above have been used by $\mathrm{Li}$ and Whalley in two recent papers which analyze the impacts of VAT basis switches on trade imbalances. Li and Whalley (2012a) apply the monetary non neutrality model to an analysis of China's VAT options since this modeling of the exchange rate regime fairly closely follows China. In Li and Whalley (2012b) they apply the intertemporal trade model to simultaneous VAT basis switches in China, the EU, and the US. 

Their results confirm the intuition that if China and Germany switch their VAT system from the present destination principle to an origin principle and the US adopts a destination principle VAT, the combined effect is to reduce imbalances for the whole world and also for all these three individual countries. This is good for global rebalancing. These changes also improve China's and Germany's welfare and increases all three countries' revenue.

\section{Concluding Remarks}

Trade rebalancing has become a major focus of discussion in the G20, and is now taken as a global objective after the 2008 financial crisis. G20 summit discussions have focused on members adjusting exchange rates. Here, I suggest that global trade models with endogenous trade imbalances can be used to also assess non exchange rate policy impacts on imbalances. For China with a large trade surplus, VAT basis switching from a destination to an origin basis may also be a significant accompanying measure yielding reductions in China's trade imbalance of over $50 \%$ and also welfare gains both for China and the world.

I summarize two recent applications of these models to VAT basis switches by Li and Whalley (2012a; $2012 b)$. In the first they show how a simple basis switch from a destination to origin basis could reduce China's trade imbalances by around $40 \%$. In the second they show significant impacts on global imbalances for simultaneous basis switches from destination to origin for Germany and China and the adoption of a destination basis VAT by the US.

\section{References}

Archibald, G. C., \& Lipsey, R. G. (1960). Monetary and Value Theory: Further Comment. The Review of Economic Studies, 28(1), 50-56.

Azariadis, C. (1993). Intertemporal macroeconomics. Cambridge, MA: Blackwell.

Dixit, A. K., \& Norman, V. (1980). Theory of international trade. Cambridge, UK: Cambridge University Press.

Genser, B. (1996). A generalized equivalence property of mixed international VAT regimes. The Scandinavian Journal of Economics, 98(2), 253-262.

Grossman, G. M. (1980). Border tax adjustments: Do they distort trade? Journal of International Economics, 10(1), 117-128.
Krauss, M. B., \& Johnson, H. G. (1974). General equilibrium analysis: A micro-economic text. London: Allen \& Unwin Publisher.

Li, C., \& Whalley, J. (2012a). Rebalancing and the Chinese VAT: Some numerical simulation results. China Economic Review, 23(2), 316-324

Li, C., \& Whalley, J. (2012b). Indirect tax initiatives and global rebalancing (NBER working paper No.17919). The National Bureau of Economic Research. Retrieved from http://www.nber.org/ papers/w17919

Patinkin, D. (1947). Multiple-Plant firms, cartels, and imperfect competition. The Quarterly Journal of Economics, 61(2), 173-205.

Patinkin, D. (1971). Inside money, monopoly bank profits, and the real-balance effect: Comment. Journal of Money, Credit and Banking, 3(2), 271275.

Whalley, J. (1979). Uniform domestic tax rates, trade distortions and economic integration. Journal of Public Economics, 11(2), 213-221.

Whalley, J., and Wang, L. (2011). The impacts of Renmimbi appreciation on trade flows and reserve accumulation in a monetary trade model. Economic Modelling, 28(2011), 614-621.

Whalley, J., Yu, J. \& Zhang, S. (2012). Trade Retaliation in a Monetary-Trade Model. Global Economy Journal, 12(1).

\section{Endnotes}

1 They can be derived by minimizing $\left(P_{L}^{j} L_{i}^{j}+P_{K}^{j} K_{i}^{j}\right)$ subject to $Q_{i}^{j}=\phi_{i}^{j}\left[\delta_{i}^{j}\left(L_{i}^{j}\right)^{\frac{\sigma_{i}-1}{\sigma_{i}^{\prime}}}+\left(1-\delta_{i}^{j}\right)\left(K_{i}^{j}\right)^{\frac{\sigma_{i}^{\prime}-1}{\sigma_{i}^{\prime}}}\right]^{\frac{\sigma_{i}^{\prime}}{\sigma_{i}^{\prime}-1}}$. 
